\section{ON THE HYPOTHESIS THAT ANIMALS ARE AUTOMATA, AND ITS HISTORY*}

$A^{\mathrm{T}}$ this period of the meeting of the British Association I am quite sure it is hardly necessary for me to call to your minds the nature of the business which takes place at our sectional meet $i_{\text {ngs. We there register the progress which science has made during }}$ the past year, and we do our best to advance that progress by original communications and free discussion. But when the honourable task of delivering this evening's lecture was imposed upon me, or rather as my friend the President has just said, when I undertook to deliver it, it occurred to me that the occasion of an evening lecture might be turned to a different purpose, that we might with much propriety and advantage turn our minds back to the past to consider what had been done by the great men of old, who "had gone down into the grave with their weapons of war, "but who had fought bravely for the cause of truth while they yet lived- to recognise their merits, and to show ourselves duly grateful for their services. I propose, therefore, to take a retrospect of the condition of that branch of science with which it is my business to be more or less familiar-not to a very remote period, for I shall go no further back than the seventeenth century, and the observations which I shall have to offer you will be confined almost entirely to the biological science of the time between the middle of the seventeenth and the middle of the eighteenth centuries. I propose to show what great ideas in biological science took their origin at that time, in what manner the speculations then originated have been developed, and in what relation they stand to what is now understood to be the body of scientific biological truth. The middle of the sixteenth century, or rather the early part of it, is one of the great epochs of biological science. It was at that time that an idea, which had been dimly advocated previously, took the solid form which can only be given to scientific ideas by the definite observation of fact-I mean the idea that vital phenomena, like all other phenomena of the physical world, are capabie of mechanical explanation, that they are reducible to law and order, and that the study of biology, in the long run, is an application of the great sciences of physics and chemistry. The man to whom we are indebted for first bringing that idea into a plain and tangible shape, I am proud to say, was an Englishman, William Harvey. Harvey was the first clearly to explain the mechanism of the circulation of the blood, and by that remarkable discovery of his, and by the clearness and precision with which be reduced that process to its mechanical elements, he laid the foundation of a scientific theory of the larger part of the processes of living beings-those processes, in fact, which we now call processes of sustentation-and by his studies of development he, further, first laid the foundation of a scientific knowledge of reproduction. But besides these great powers of living beings, there remains another class of functions-those of the nervous system-with which Harvey did not grapple. It was, incleed, left for a contemporary of his, a man who, as he himself tells us, was mainly stimulated in these inquiries by the brilliant researches of Harvey-Réné Descartes-to play a part in relation to the phenomena of the nervous system, which, in my judgment, is equal in value to that which Harvey played in regard to the circulation. And when we consider who Descartes was, how brief the span of his life, I think it is a truly wonderful circumstance that this man, who died at fiftyfour, should be one of the recognised learlers of philosophythat, as I am informed by competent authority, he was one of the first and most original mathematicians who has ever lived, and that, at the same time, the fertility of his intellect and the grasp of his genius should have been so great that he could take rank, as I believe he must, beside the immorial Harvey as a physiologist. And you must recollect that Descartes was not m rely, as some had been, a happy speculator. He was a working anatomist and physiologist, conversant with all the anatomical and physiological lore of his time, and practised in all meihods by which anatomical and physiological discoveries were then made ; and it is rela ed of him-and a most characteristic anecdote it is, and one which should ever put to silence those shallow talkers who speak of Descartes as a merely hypothetical and speculative philosopher-that a friend once calling upon him in Holland begged to be shown his library. Descartes led him into a sort of shed, and, drawing aside a curtain, displayed a dissecting-room full of bodies of animals in course of dissection, and said, "There is my library." It would

* Address by Irof. Huxley, F.R.S., at the Fritish Association, Belfast. take us a very long time if I were to attempt to pursue the method which would be requisite for the full establishment of all that I am about to say; that is to say, if I were to quote the several passages of Descartess works which bear out my ascription to him of the several propositions which $\mathrm{I}$ am going to bring before you. And I must beg you, therefore, to be so good as to take it on my authority for the present, although for the present only, that there are to be found clearly expressed in Descartes' works the propositions which I shall proceed to lay before you, and each of which I shall compare as we go on, as briefly as may be, with the existing state of physiological science, in order that you may see in what position with respect to physiology-ay, even to the advanced physiology of the present time--this man stood. And, happily, the matters with which we shall treat are such as to require no extensive knowledge of anatony-no more, in fact, than such as, I presume, must be familiar to almost every person.

I think I need only premise that what we call the nervous system in one of the higher animals consists of a central apparatus, composed of the brain, which is lodged in the skull, and of a cord pruceeding from it, which is termed the spinal marrow, and which is lodged in the vertebral column or spine, and that from these soft white masses-for such they arethere proceed cords which are termed nerves, some of which nerves end in the muscles, while others end in the organs of sensation. That bare and bald statement of the fundamental composition of the nervous system will be enough for our present purpose.

The first proposition culled from the works of Descartes which I have to lay before you, is one which will sound very familiar. It is the view, which he was the first, so far as I know, to state, not only definitely, but upon sufficient grounds, that the brain is the organ of sensation, of thought, and of emotion-using the word "organ" in this sense, that certain changes which take place in the matter of the brain are the essential antecedents of those states of consciousness which we term sensation, thought, and emotion. Nowadays that is part of popular and familiar knowledge. If your friend disagrees with your opinion, runs amuck against any of your pet prejudices, you say, " $\mathrm{Ah}$ ! poor fellow, he is a little touched here ;" by which you mean that his brain is not doing its business properly, and, therefore, that he is not thinking properly. But in Descartes' time, and I may say for 150 years afterwards, the best physiologists had not reacher that point. It remained down to the time of Bichat a question whether the passions were or were not located in the abdominal viscera. This, therefore, was a very great step. It is a statement which Descartes makes from the beginning, and from which he never swerves. In the second place, Descartes lays down the proposition that all the movements of animal bodies are effected by the change of form of a certain part of the matter of their bodies, to which he applies the general term of muscle. You must be aware of this in reading Descartes; you must use the terms in the sense in which he used them, or you will not understand him. That is a proposition which is now placed beyond all doubt whatever. If I move my arm, that movement is due to the change of this mass of flesh in front called the biceps muscle: it is shortened and it becomes thicker. If I move any of my limbs the reason is the same. As I now speak to you, the different tones of my voice are due to the exquisitely accurate adjustment of the contractions of a multitude of such portions of flesh; and there is no considerable and visible movement of the animal body which is not, as Descartes says, resolvable into these changes in the form of matter termed muscle. But Descartes went further, and he stated that in the normal and ordinary condition of things, these changes in the form of muscle in the living body only occur under certain conditions; and the essential condition of the change is, says Descartes, the motion of the matter contained within the nerves, which go from the central apparatus to the muscle. Descartes gave this moving material a particular name-the animal spirits. Nowadays we should not talk of the existence of animal spirits, but we should say that a molecular change takes place in the nerve, and that that molecular change is propagated with a certain velocity, from the central apparatus to the muscle. Nevertheless, the modification of the idea is not greater than that which has taken place in our view of electricity, in our change of conception of it as a fluid to our conception of it as a condition of propagated molecular change. Modern physiology has measured the rate of the change to which I have referred; it has thrown marvellous light upon its nature; it has increased cur knowledge of its characters, but the fundamental conception 
remains exactly what it was in the time of Descartes. Next, Descartes says that, under ordinary circumstances, this change in the contents of a nerve, which gives rise to the contraction of a muscle, is produced by a change in the central nervous apparatus, as, for example, in the brain. We say at the present time exactly the same thing. Descartes said that the animal spirits were stored up in the brain, and flowed out along the motor nerves. We say that a molecular change takes place in the brain that is propagated along the motor nerve. The evidence of that is abundantly supplied by experimental research. Further, Descartes stated that the sensory organs, or those apparatuses which give rise to our feelings when acted upon by the influences which produce sensation, caused a change in the sensory nerves, which he described as a flow of animal spirits along those nerves, which flow was propagated to the brain. If I look at this candle which I hold before me, the light falling on the retina of my eye gives rise to an affection of the optic nerve, which affection Descartes described as a flow of the animal spirits to the brain. We should now speak of it as a molecular change propagated along the optic nerve to the brain; but the fundamental idea is the same. In all our notions of the operations of nerve we are building upon Descartes' foundation. Not only so, but Descartes lays down over and over again, in the most distinct manner, a proposition which is of paramount importance not only for physiology but for psychology. He says that when a body which is competent to produce a sensation touches the sensory organs, what happens is the production of a mode of motion of the sensory nerves. That mode of motion is propagated to the brain. That which takes place in the brain is still nothing but a mode of motion. But, in addition to this mode of motion, there is, as everybody can find by experiment for himself, something else which can in no way be compared to motion, which is utterly unlike it, and which is that state of consciousness which we call a sensation. Descartes insists over and over again upon this total disparity between the agent which excites the state of consciousness and the state of consciousness itself. He tells us that our sensations are not pictures of external things, but that they are symbols or signs of them; and in doing that he made one of the greatest possible revolutions, not only in physiology but in philosophy. Till his time it was conceived that visible bodies, for example, gave from themselves a kind of film which entered the eye and so went to the brain, species intentionales as they were called, and thus the mind received an actual copy or picture of things which were given off from it. It is to Descartes we owe that complete revolution in our ideas, which has led us to see that we have really no knowledge whatever of the causes of those phenomena which we term external things, and that the only certainty we possess is that they cannot be like those phenomena. In laying down that proposition upon what $I$ imagine to be a perfectly irrefragable basis, Descartes laid the foundation of that form of philosophy which is termed idealism, which was subsequently expanded to its uttermost by Berkeley, and has since taken very various shapes.

But Descartes noticed not only that under certain conditions an impulse made by the sensory organ may give rise to a sensation, but that under certain other conclitions it may give rise to motion, and that this motion may be effected without sensation, and not only without volition, but even contrary to it. I trouble you with as little reading as I can, because it occupies so much time; but I must ask your patience for one very remarkable passage which is contained in the answer that Descartes gave to the objections raised by the famous Port Royalist Arnauld to his Fourth Meditation. Descartes says: "It appears to me to be a very remarkable circumstance that no movement can take place either in the bodies of beasts or even in our own, if these bodies have not in themseives all the organs and instruments by means of which the very same movement would be accomplished in a machine, so that, even in us, the spirit or the soul does not directiy move the limb, but only determines the course of that very subtle liquid which is called the animal spirits, which, running continually from the heart by the brain into the muscles, is the cause of all the movements of our limbs, and often may cause many different motions, one as easily as the other. And it does not even aiways exert this determination, for, among the movements which take place in us, there are many which do not depend upon the mind at all, such as the beating of the heart, the digestion of food, the nutrition, the respiration of those who sleep, and, even in those who are awake, walking, singing, and other similar actions when they are nerformed without the mind thinking about them. And when one who falls from a height throws his hands forward to save his head, it is in virtue of no ratiocination that he performs this action; it does not depend upon his mind, but takes place merely because his senses, being affected by the present danger, cause some change in his brain, which determines the animal spirits to pass thence into the nerves in such a manner as is required to produce this motion, in the same way as in a machine, and without the mind being able to hinder it." I know in no modern treatise of a more clear and precise statement, of a more perfect illustration than this of what we understand by the automatic action of the brain. And what is very remarkable, in speaking of these movements which arise by a sensation being as it were reflected from the central apparatus into a limb-as, for example, when one's finger is pricked and the arm is suddenly drawn up, the motion of the sensory nerve travels to the spine and is again reflected down to the muscles of the arm-Descartes uses the very phrase that we at this present time employ; he speaks of the "esprits réfléchis," the reflected spirits; and that this was no mere happy phrase lost upon his contemporaries will be obvious if you consult the famous work of Willis, the Oxford professor, "De Anima Brutorum," which was published about 1672 . In giving an account of Descartes' views he borrows this very phrase from him, and speaks of this reflection of the motion of a sensory nerve into the motion of a motor nerve, "sicut undulatione reflexa," as if it were a wave thrown back; so that we have not only the thing reflex action described, but we have the phrase "reflex" recognised in its full significance.

And the last great service to the physiology of the nervous system which $I$ have to mention as rendered by Descartes was this, that he first, so far as I know, sketched out a physical theory of memory. What he tells you in substance is this, that when a sensation takes place, the animal spirits travel up the sensory nerve, pass to the appropriate part of the brain, and there, as it were, find their way through the pores of the substance of the brain. And he says that when this has once taken place, when the particles of the brain have themselves been, as it were, shoved aside a little by a single passage of the animal spirits, the passage is made easier in the same direction for any subsequent flow of animal spirits; and that the repetition of this action makes it easier still, until, at length, it becomes very easy for the animal spirits to move these particular particles of the brain, the motion of which gives rise to the appropriate sensation; and, finally, the passage is so easy that almost any impulse which stirs the animal spirits causes them to flow into these already open pores more easily than they would flow in any other direction; and the flow of the animal spirits recalls the image, the state of consciousness called into existence by a former sensory impression. This view is essentially at one with all our present physical theories of memory. That memory is dependent upon a physical process stands beyond question. The results of the study of disease, the results of the action of poisonous substances, all conclusively point to the fact that memory is inseparably connected with the integrity of certain material parts of the brain and dependent upon them, and I know of no hypothesis by which this fact can be accounted for except by one which is essentially similar to the notion of Descartes, a notion that the impression once made makes subsequent impressions easier and therefore allows almost any indirect disturbance of the brain to call up this particular image.

So far, the ideas started by Descartes have simply been expanded, enlarged, and defined by modern research ; they are the keystones of the modern physiology of the nervous system. But in one respect Descartes proceeded further than any of his contemporaries, and has been followed by very few of his successors in later days, although his views were for the best part of a century largely dominant over the intellectual mind of Europe. Descartes reasoned thus: "I can account for many of the actions of living beings mechanically, since reflex actions take place without the intervention of consciousness, and even in opposition to the will." As, for example, when a man in falling mechanically puts out his hand to save himself, or when a person, to use another of Descartes' illustrations, strikes at his friend's eye, and although the friend knows he does not mean to hit him, he nevertheless cannot prevent the muscles of his eye from winking. "In these cases," Descartes said, "I have clear evidence that the nervous system acts mechanically without the intervention of consciousness and without the intervention of the will, or, it may be, in opposition to it. Why, then, may I not extend this idea further? As actions of a certain amount of complexity are brought about in this way, why may not actions of still greater 
complexity be so produced? Why, in fact, may it not be that the whole of man's physical actions are mechanical, his mind living apart, as it were, and only occasionally interfering by means of volition?" And it so happened that Descartes was led by some of his speculations to believe that beasts had no souls, and consequently could have no consciousness; and thus, his two ideas harmonising together, he developed that famous hypothesis of the automatism of brutes, which is the main subject of my present discourse. What Descartes meant by this was that animals are absolute machines, as if they were mills or barrel organs; that they have no feelings; that a dog does not see, and does not hear, and does not smell, but that the impressions which would produce those states of consciousness in ourselves, give rise in the dog, by a mechanical reflex process, to actions which correspond to those which we perform when we do smell, and do taste, and do see. On the face of it this appears to be a most surprising hypothesis, and I do not wonder that it proved to be a stumbling-block even to such acute and subtle men as Henry More, who was one of Descartes' correspondents; and yet it is a very singular thing that this, the boldest and most paradoxical notion which Descartes broached, has received as much and as strong support from modern physiological research as any other of his hypotheses. I will endeavour to explain to you in as few words as possible what is the nature of that support, and why it is that Descartes' hypothesis, although I am bound to say I do not agree with it, nevertheless, remains at this present time not only quite as defensible as it was in his own time, but I should say, upon the whole, a little more defensible.

If it should happen to a man that by accident his spinal cord is divided, he would become paralysed below the point of injury. In such case his limbs would be absolutely paralysed; he would have no control over them, and they would be devoid of sensation. You might prick his feet, or burn them, or do anything else you like with them, and they would be absolutely insensible. Consciousness, therefore, so far as we can have any knowledge of it, would be entirely abolished in that part of the central nervous apparatus which lies below the injury. But although the man under these circumstances is paralysed in the sense of not being able to move his own limbs, he is not paralysed in the sense of their being deprived of motion, for if you tickle the soles of his feet with a feather the limbs will be drawn up just as vigorously, perhaps a little more vigorously, than when he was in full possession of the consciousness of what happened to him. Now, that is a reflex action. The impression is transmitted from the skin to the spinal cord, it is reflected from the spinal cord, and passes down into the muscles of the limbs, and they are dragged up in this manner-dragged away from the sources of irritation, though the action, you will observe, is a purely automatic or mechanical action. Suppose we deal with a frog in the same way, and cut across the spinal cord. The frog falls into precisely the same condition. So far as the frog is concerned, his limbs are useless; but you have merely to apply the slightest irritation to the skin of the foot, and the limb is instantly drawn away. Now, if we have any ground for argument at all, we have a right to assume that, under these circumstances, the lower half of the frog's body is as devoid of consciousness as is the lower half of the man's body; and that the bocly of the frog below the injury is in this case absolutely devoid of consciousness, is a mere machine like a musical box or a barrel-organ, or a watch. You will remark, moreover, that the movement of the limbs is purposive-that is to say, that when you irritate the skin of the foot, the foot is drawn away from the danger, just as it would be if the frog were conscious and rational, and could act in accordance with rational consciousness. Put you may say it is easy enough to understand how so simple an action might take place mechanically.

Let us consider another experiment. Take this creature, which certainly cannot feel, and touch the skin of the side of the body with a little acetic acid, a little vinegar, which in a frog that could feel would give rise to great pain. In this case there can be no pain, because the application is made below the point of section; nevertheless, the frog lifts up the limb of the same side, and applies the foot to rubbing off the acetic acid; and, what is still more remarkable, if you hold down the limb so that the frog cannot use it, he will, by and by, take the limb of the other side and turn it across the body, and use it for the same rubbing process. It is impossible that the frog, if it were in its entirety and were reasoning, could perform actions more purposive than these, and yet we have most complete assurance that in this case the frog is not acting from purpose, has no con- sciousness, is a mere automatic machine. But now suppose that instead of making your section of the cord in the middle of the body, you had made it in such a manner as to divide the hindermost part of the brain from the foremost part of the brain, and suppose the foremost two-thirds of the brain entirely taken away, the frog is then absolutely devoid of any spontaneity; it will remain for ever where you leave it; it will not stir unless it is touched; it sits upright in the condition in which a frog habitually does sit; but it differs from the frog which $I$ have just described in this, that if you throw it into the water it begins to swim-swims just as well as the perfect frog does. Now, swimming, you know, requires the combination, and indeed the very careful and delicate combination, of a great number of muscular actions, and the only way we can account for this is, that the impression made upon the sensory nerves of the skin of the frog by the contact of the water, conveys to the central nervous apparatus a stimulus which sets going a certain machinery by which all the muscles of swimming are brought into play in due order and succession. Moreover, if the frog be stimulated, be touched by some irritating body, although we are quite certain it cannot feel, it jumps or walks as well as the complete frog can do. But it cannot do more than this.

Suppose yet one other experiment. Suppose that all that is taken away of the brain is what we call the cerebral hemispheres, the most anterior part of the brain. If that operation is properly performed, the frog may be kept in a state of full bodily vigour for months, or it may be for years; but it will sit for ever in the same spot. It sees nothing; it hears nothing. It will starve sooner than feed itself, although if food is put into its mouth it swallows it. On irritation it jumps or walks; if thrown into the water it swims. But the most remarkable thing that it does is this--you put it in the flat of your hand; it sits there, crouched, perfectly quiet, and would sit there for ever. Then if you incline your hand, doing it very gently and slowly, so that the frog would naturally tend to slip off, you feel the creature's fore-paws getting a little slowly on to the edge of your hand until he can just hold himself there, so that he does not fall ; then, if you turn your hand, he mounts up with great care and deliberation, putting one leg in front and then another, until he balances himself with perfect precision upon the edge of your hand; then if you turn your hand over, he goes through the opposite set of operations until he comes to sit in perfect security upon the back of your hand. The doing of all this requires a delicacy of co-ordination, and an adjustment of the muscular apparatus of the body which is only comparable to that of a rope-dancer among ourselves; though in truth a frog is an animal very poorly constructed for rope-dancing, and on the whole we may give him rather more credit than we should to a human dancer. These movements are performed with the utmost steadiness and precision, and you may vary the position of your hand, and the frog, so long as you are reasonably slow in your movements, will work backwards and forwards like a clock. And what is still more wonderful is, that if you put the frog on a table, and put a book between him and the light, and give him a little jog behind, he will jump-take a long jump, very possibly--but he won't jump against the book; he will jump to the right or to the left, but he will get out of the way, showing that although he is absolutely insensible to ordinary im. pressions of light, there is still a something which passes through the sensory nerve, acts upon the machinery of his nervous system, and causes it to adapt itself to the proper action.

Can we go further than this? I need not say that since those days of commencing anatomical science when criminals were handed over to the doctors, we cannot make experiments on human beings, but sometimes they are made for us, and made in a very remarkable manner. That operation called war is a great series of physiological experiments, and sometimes it happens that these physiological experiments bear very remarkable fruit. I am indebted to my friend General Strachey for bringing to my notice an account of a case which appeared within the last four or five days in the scientific article of the Fournal des Débats. A French soldier, a sergeant, was wounded at the battle of Bazeilles, one, as you recollect, of the most fiercely contested battles of the late war. The man was shot in the head, in the region of what we call the left parietal bone. The bullet fractured the bone. The sergeant had enough vigour left to send his bayonet through the Prussian who shot him. Then he wandered a few hundred yards out of the village, fell senseless, but, after the action, was picked up and taken to the hospital, where he remained some time. When he came to himself, as usual in such cases of injury, he was para. lysed on the opposite side of the body, that is to say, the right arm and the right leg were completely paralysed. That state of 
things lasted, $I$ think, the better part of two years, but sooner or later he recovered from it, and now he is able to walk about with activity, and only by careful measurement can any difference between the two sides and his body be ascertained. The inquiry, the main results of which I shall give you, has been conducted by exceedingly competent persons, and they report that at present this man lives two lives, a normal life and an abnormal life. In his normal life he is perfectly well, cheerful, does his work as a hospital attendant, and is a respectable, well-conducted man. This normal life lasts for about seven-and-twenty days, or thereabouts, out of every month; but for a day or two in each month he passes suddenly and without any obvious change into his abnormal condition. In this state of abnormal life he is still active, goes about as usual, and is to all appearance just the same man as before, goes to bed and undresses himself, gets up, makes his cigarette and smokes it, and eats and drinks. But he neither sees, nor hears, nor tastes, nor smells, nor is he conscious of anything whatever, and he has only one sense organ in a state of activity, namely, that of touch, which is exceedingly delicate. If you put an obstacle in his way, he knocks against it, feels it and goes to the one side ; if you push him in any direction, he goes straight on until something stops him. I have said that he makes his cigarettes, but you may supply him with shavings or of anything else instead of tobacco, and still he will go on making his cigarettes as usual. His actions are purely mechanical. He feeds voraciously, but whether you give him aloes or assafotida, or the nicest thing possible, it is all the same to him. The man is in a condition absolutely parallel to that of the frog I have just described, and no doubt when he is in this condition the functions of his cerebral hemispheres are, at any rate, largely annihilated. He is very nearly -I don't say wholly, but very nearly - in the condition of an animal in which the cerebial hemispheres are extirpated. And his state is wonderfully interesting to me, for it bears on the phenomena of mesmerism, of which I saw a good deal when I was a young man. In this state he is capable of performing all sorts of actions on mere suggestion. For example, he dropped his cane, and a person near him putting it into his hand, the feeling of the end of the cane evidently produced in him those molecular changes of the brain which, had he possessed consciousness, would have given rise to the idea of his rifle; for he threw himself on his face, began feeling for his cartridges, went through the motions of touching his gun, and shouted out to an imaginary comrade, "Here they are, a score of them ; but we will give a good account of them." But the most remarkable fact of all is the modification which this injury has made in the man's moral nature. In his normal life he is an upright and honest man. In his abnormal state he is an inveterate thief. $\mathrm{He}$ will steal everything he can lay his hands upon, and if he cannot steal anything else, he will steal his own things and hide them away.

Now, if Descartes had had this fact before him, need I tell you that his theory of animal automatism would have been enormously strengthened? He would have said: "Here is a case of a man performing actions more complicated, and to all appearance more dependent on reason, than any of the ordinary operations of animals, and yet you have positive proof that these actions are purely mechanical. What, then, have you to urge against my doctrine that all animals are mere machines?" In the words of Malebranche, who adopted Descartes' view, "In dogs, cats, and other animals, there is neither intelligence nor piritual soul as we understand the matter commonly; they eat without pleasure, they cry out without pain, they grow without knowing it, they desire nothing, they know nothing, and if they act with dexterity and in a manner which indicates intelligence, it is because God having made them with the intention of preserving them, He has constructed their bodies in such a manner that they escape organically, without knowing it, everything which could injure them and which they seem to fear." Descartes put forward this hypothesis, and I do not know that it can be positively refuted. We can have no direct observation of consciousness in any creature but ourselves. But I must say for myself--looking at the matter on the ground of analogytaking into account that great doctrine of continuity which forbids one to suppose that any natural phenomena can come into existence suddenly and without some precedent, gradual modification tending towards it, and taking into account the incontrovertible fact that the lower vertebrated animals possess, in a less developed condition, that part of the brain which we have every reason to believe is the organ of consciousness in ourselves, it seems vastly more probable that the lower animals, although they may not possess that sort of consciousuess which we have ourselves, yet have it in a form proportional to the comparative de. velopment of the organ of that consciousness, and foreshadow more or less dimly those feelings which we possess ourselves. I think that is the most rational conclusion that can be come to. It has this advantage, though this is a consideration which could not be urged in dealing with questions that are susceptible of demonstration, but which is well worthy of consideration in a case like the present, that it relieves us of the very terrible consequences of making any mistake on this subject. I must confess that, looking at the terrible struggle for existence which is everywhere going on in the animal world, and considering the frightful quantity of pain with which that process must be accompanied, if animals are sensitive, I should be glad if the probabilities were in favour of the view of Descartes. But, on the other hand, considering that if we were to regard animals as mere machines, we might indulge in unnecessary cruelties and in careless treatment of them, I must confess I think it much better to err on the right side, and not to concur with Descartes on this point.

But let me point out to you that although we may come to the conclusion that Descartes was wrong in supposing that animals are insensible machines, it does not in the slighest degree follow that they are not sensitive and conscious automata ; in fact, that is the view which is more or less clearly in the minds of every one of us. When we talk of the lower animals being provided with instinct, and not with reason, what we really mean is, tha although they are sensitive and although they are conscious, yet they act mechanically, and that their different states of consciousness, their sensations, their thoughts (if they have any), their volitions (if they have any), are the products and consequences of their mechanical arrangements. I must confess that this popular view is to my mind the only one which can be scientifically adopted. We are bound by everything we know of the operations of the nervous system to believe that when a certain molecular change is brought about in the central part of the nervous system, that change, in some way utterly unknown to us, causes that state of consciousness that we term a sensation. It is not to be doubted that those motions which give rise to sensation leave in the brain changes of its substance which answer to what Haller called "vestivia rerum," and to what that great thinker, David Hartley, termed "Vibratiuncules." The sensation which has passed away leaves behind molecules of the brain competent to its reproduction-"sensigenous molecules," so to speak-which constitute the physical foundation of memory. Other molecular changes give rise to conditions of pleasure and pain, and to the emotion which in ourselves we call volition. I have no doubt that is the relation between the physical processes of the animal and his mental processes. In this case it follows inevitably that these states of consciousness can have no sort of relation of causation to the motions of the muscles of the body. The volitions of animals will be simply states of emotion which precede their actions. To make clear what I mean, suppose I had a frog placed in my hand, and that I could make it, by turning my hand, perform this halancing movement. If the frog were a philosopher, he might reason thus :-- "I feel myself uncomfortable and slipping, and, feeling myself uncomfortable, I put my legs out to save myself. Knowing that I shall tumble if I do not put them further, I put them further still, and my volition brings about all these beautiful adjustments which result in my sitting safely." But if the frog so reasoned, he would be entirely mistaken.; for the frog does the thing just as well when he has no reason, no sensation, no possibility of thought of any kind. The only conclusion, then, at which there seems any good ground for arriving is that animals are machines, but that they are conscious machines.

I might with propriety consider what I have now said as the conclusion of the observations which I have to offer concerning animal automatism. So far as $I$ know, the problem which we have hitherto been discussing is an entirely open one. I do not know that there is any reason why any person, whatever his opinions may be, should be prevented, if he be so inclined, from accepting the doctrine which I have just now put before you. So far as we know, animals are conscious automata. That doctrine is perfectly consistent with any view that we may choose to take on the very curious speculation--Whether animals possess souls or not, and if they possess souls, whether those souls are immortal or not. The doctrine to which I have referred is not inconsistent with the perfectly strict and literal adherence to the Scripture text concerning "the beast that perisheth," nor, on the other hand, does it prevent anyone from entertaining the amiable con- 
victions ascribed by Pope to his untutored savage, that when he passed to the realms of the blessed "his faithful dog should bear him company." In fact, all these accessory questions to which I have referred involve problems which cannot be discussed by physical science, inasmuch as they do not lie within the scope of physical science, but come into the province of that great mother of all science, Philosophy. Before any direct answer can be given upon any of these questions we must hear what Philosophy has to say for or against the views that may be held. I need hardly say-especially having detained you so long as I find I have done- that I do not propose to enter into that region of discussion, and I might, properly enough, finish what I have to say upon the subject-especially as I have reached its natural limits-if it were not that an experience, now, I am sorry to say, extending over a good many years, leads me to anticipate that what I have brought before you to-night is not likely to escape the fate which, upon many occasions within my recollection, has attended statements of scientific doctrine and of the conclusions towards which science is tending, which have been made in a spirit intended at any rate to be as calm and as judicial as that in which I have now laid these facts before you. I do not doubt that the fate which has befallen better men will befall me, and that I shall have to bear in patience the reiterated assertion that doctrines such as I have put before you have very evil tendencies. I should not wonder if you were to be told by persons speaking with authority-not, perhaps, with that authority which is based upon knowledge and wisdom, but still with authority-that my intention in bringing this subject before you is to lead you to apply the doctrine I have stated, to man as well as brutes, and it will then certainly be further asserted that the logical tendency of such a doctrine is Fatalism, Materialism, and Atheism. Now, let me ask you to listen to another product of that long experience to which I referred. Logical consequences are very important; but in the course of my experience I have found that they are the scarecrows of fools and the beacons of wise men. Logical consequences can take care of themselves. The only question for any man to ask is- "Is this doctrine true, or is it false?" No other guestion can possibly be taken into consideration until that one is settled. And, as I have said, the logical consequences of doctrines can only serve as a warning to wise men to ponder well whether the doctrine submitted for their consideration be true or not, and to test it in every possible direction. Undoubtedly I do hold that the view I have taken of the relations between the physical and mental faculties of brutes applies in its fulness and entirety to man ; and if it were true that the logical consequences of that belief must land me in all these terrible consequences, I should not hesitate in allowing myself to be so landed. I should conceive that if I refused I should have done the greatest and most abominable violence to everything which is deepest in my moral nature. But now I beg leave to say that, in my conviction, there is no such logical comection as is pretended between the doctrine I accept and the consequences which people profess to draw from it. Sorne years ago I had occasion, in dealing with the philosophy of Descartes, and some other matters, to state my conviction pretty fully on those sub. jecls, and, although I know from experience how futile it is to endeavour to escape from those nicknames which many people mistake for argument, yet, if those who care to investigate these questions in a spirit of candour and justice will look into those writings of mine, they will see my reasons for not imagining that such conclusions can be drawn from such premises. To those who do not look into these matters with candour and with a desire to know the truth, I have nothing whatever to say, except to warn them on their own behalf what they do ; for assuredly if, for preaching such doctrine as I have preached to you to-night, I am cited before the bar of public opinion, I shall not stand there alone. On my one hand I shall have, among theologians, St. Augustine, John Calvin, and a man whose name should be well known to the Presbyterians of Ulster-Jonathan Edwardsunless, indeed, it be the fashion to neglect the study of the great masters of divinity, as many other great studies are neglected nowadays; and I should have upon my other hand, among philosophers, Leibnitz; I should have Père Malebranche, who saw all things in God; I should have David Hartley, the theologian as well as philosopher; I should have Charles Bonnet, the eminent naturalist, and one of the most zealous defender Christianity has ever had. I think I should have, within easy reach, at any rate John Locke. Certainly the school of Descartes would be there, if not their master ; and I am inclined to think that, in due justice, a citation would have to be served upon Immanuel Kant himself. In such society it may be better to be a prisoner than a judge; but I would ask those who are likely to be influenced by the din and clamour which are raised about these questions, whether they are more likely to be right in assuming that those great men $I$ have mentioned-the fathers of the Church and the fathers of Philosophy-knew what they were about; or that the pigmies who raise the din know betler than they did what they meant. It is not necessary for any man to occupy himself with problems of this kind unless he so choose. Life is full enough, filled to the brim, by the performance of its ordinary duties ; but let me warn you, let me beg you to believe, that if a man elect to give a judgment upon these great questions; still more, if he assume to himself the responsibility of attaching praise or blame to his fellow-men for the judgments which they may venture to express--then, unless he would commit a sin more grievous than most of the breaches of the Decalogue, he must avoid a lazy reliance upon the information that is gathered by prejudice and filtered through passion. Let him go to those great sources that are open to him as to every one, and to no man more open than to an Englishman; let him go back to the facts of nature, and to the thoughts of those wise men who for generations past have been the interpreters of nature.

\section{THE CARNIVOROUS HABITS OF PLANTS*}

I HAVE chosen for the subject of my address to you from the chair in which the Council of the British Association has done me the honour of placing me, the carnivorous habits of some of our brother-organisms-Plants.

Various observers have described with more or less accuracy the habits of such vegetable sportsmen as the Sundew, the Venus's Fly-trap, and the Pitcher-plants, but few have inquired into their motives; and the views of those who have most accurately appreciated these have not met with that general acceptance which they deserved.

Quile recently the subject has acquired a new interest, from the researches of Mr. Darwin into the phenomena which accompany the placing albuminous substances on the leaves of Drosera and Pinguicula, and which, in the opinion of a very eminent physiologist, prove, in the case of Dionæa, that this plant digests exactly the same substances and in exactly the same way that the human stomach does. With these researches Mr. Darwin is still actively engaged, and it has been with the view of rendering him such aid as my position and opportunities at Kew afforded me, that I have, under his instructions, examined some other carnivorous plants.

In the course of my inquiries I have been led to look into the early history of the whole subject, which I find to be solittle known and so interesting that $I$ have thought that a sketch of it, up to the date of Mr. Darwin's investigations, might prove acceptable to the members of this Association. In drawing it up, I have been obliged to limit myself to the most important plants ; and with regard to such of these as Mr. Darwin has studied, I leave it to him to announce the discoveries which, with his usual frankness, he has communicated to me and to other friends; whilst with regard to those which I have myself studied, Sarracenia and Nepenthes, I shall briefly detail such of my observations and experiments as seem to be the most suggestive.

Dionca.-About I 768 Ellis, a well-known English naturalist, sent to Linnæus a drawing of a plant, to which he gave the poetical name of Dionza. "In the year 1765 ," he writes, " our late worthy friend, Mr. Peter Collinson, sent me a dried specimen of this curious plant, which he had received from Mr. John Bartram, of Philadelphia, botanist to the late King." Ellis flowered the plant in his chambers, having obtained living specimens from America. I will read the account which he gave of it to Linnreus, and which moved the great naturalist to declare that, though he had seen and examined no small number of plants, he had never met with so wonderful a phenomenon :-

"The plant, Ellis says, shows that Nature may have some views towards its nourishment, in forming the upper joint of its leaf like a machine to catch food ; upon the middle of this lies the bait for the unhappy insect that becomes its prey. Many minute red glands that cover its surface, and which perhaps discharge sweet liquor, tempts the animal to taste them; and the instant these tender parts are irritated by its feet, the two lobes rise up, grasp it fast, lock the rows of spines together, and squeeze it to death. And further, lest the strong efforts for life in the creature just taken should serve to disengage it, three * Address in the Department of Zoology and Botany, British Association, Belfast, August 2I, by Dr. Hooker, C. B., D.C.L.., Pres. R.S. 